Wiraraja Medika : Jurnal Kesehatan
https://www.ejournalwiraraja.com/index.php/FIK
2088-415x (Print)|2685-9998 (online)

\title{
Analisis Faktor Kepatuhan Berobat Penderita Tuberculosis Paru Di Bandung
}

\section{Upik Rahmi}

Program Studi Keperawatan, Fakultas Pendidikan Olah Raga dan Kesehatan, Universitas Pendidikan Indonesia, Indonesia, upikrahmi@upi.edu* *Corresponding author

\begin{tabular}{|c|c|}
\hline INFORMASI ARTIKEL & ABSTRAK \\
\hline $\begin{array}{l}\text { Received: 10-04-2020 } \\
\text { Revised: 17-04-2020 } \\
\text { Accepted: 20-04-2020 } \\
\text { Kata Kunci: } \\
\text { Tuberculosis paru, } \\
\text { Kepatuhan, Berobat }\end{array}$ & $\begin{array}{l}\text { Tuberkulosis merupakan masalah kesehatan yang belum dapat diatasi. } \\
\text { Masalah tersebut disebabkan karena beberapa faktor salah satunya } \\
\text { ketidakpatuhan pasien terhadap pengobatan. Di Indonesia insiden kasus TB } \\
\text { sejumlah } 842.000 \text { per tahun dan notifikasi kasus TB } 569.899 \text {, maka masih } \\
\text { ada } 32 \% \text { belum ternotifikasi dengan baik karena belum terjangkau, belum } \\
\text { terdeteksi maupun tidak terlaporkan. Dari angka insiden ini dilakukan } \\
\text { perhitungan beban kasus TB di provinsi dan kabupaten/kota. Penelitian ini } \\
\text { bertujuan untuk Mengidentifikasi faktor yang berhubungan dengan } \\
\text { kepatuhan pasien terhadap pengobatan TB paru di wilayah kerja Puskesmas } \\
\text { Garuda Bandung. Metodelogi penelitian dengan studi kasus analitik, desain } \\
\text { case control dengan jumlah Sampel penelitian } 43 \text { orang pasien TB paru } \\
\text { diambil secara total dan yang gagal akan dikeluarkan dari pengobatan. } \\
\text { Instrumen penelitian ini menggunakan kuesioner dengan Analisis data chi } \\
\text { square. Hasil: Faktor yang paling dominan adalah Jenis Kelamin dengan } P \\
\text { value (0.014) dan pekerjaan Pvalue (0.025) dimana p < } 0,05 \text { sedangkan } \\
\text { faktor yang tidak berhubungan usia, pengetahuan, pendidikan, dan } \\
\text { pendapatan keluarga, p }>0.05 \text {. Kesimpulan: Jenis kelamin dan pekerjaan } \\
\text { memiliki hubungan yang signifikan terhadap kepatuhan berobat } \\
\text { sedangkan Usia, Pengetahuan dan Pendapatan tidak ada hubungan } \\
\text { terhadap kepatuhan berobat penderita Tuberculosis. }\end{array}$ \\
\hline
\end{tabular}

\section{ABSTRACT}

\section{Keywords:}

Pulmonary tuberculosis, compliance, Medicine
Tuberculosis (TB) is one of the public health problems that cannot be overcome. The problem is caused by several factors, one of which is the noncompliance of patients with treatment. In Indonesia, the incidence of TB cases is 842,000 per year and notification of TB cases is 569,899 cases, so there are still around $32 \%$ of the cases that have not been verified either unreached, undetected or not reported. From this incident rate the TB burden is calculated in each province and district / city, (Indonesia, 2019). Purpose: Identify factors related to adherence to the treatment of pulmonary $T B$ patients in the working area of Garuda Bandung Puskesmas. Method: This is an analytic case study with a case control design. The sample of this study was 43 pulmonary TB patients taken in total who failed and were removed from treatment in 2017. The research instrument used a questionnaire. Data analysis using chi square. Results: The most dominant factors affecting adherence to treatment among pulmonary TB patients were Gender P value (0.014) and occupational Pvalue (0.025) where $p<0.05$ while factors not related to medication adherence were age, knowledge, education, and family income, $p>0.05$. Conclusion: Gender and occupation have a significant relationship to tuberculosis treatment adherence, while age, knowledge and family income have no significant relationship to tuberculosis patient adherence. 


\section{PENDAHULUAN}

Kasus penyakit Tuberculosis (TB) masih banyak terjadi di dunia. Tahun 2018, Kasus TB baru terjadi di wilayah Asia Tenggara 44\% , wilayah Afrika 24\% dan Pasifik Barat 18\% kasus. Tahun 2018, 87\% kasus TB baru terjadi pada 30 negara. Kasus TB baru di India, Cina, Indonesia, Filipina, Pakistan, Nigeria, Bangladesh, dan Afrika Selatan, (WORLD HEALTH ORGANISATION, 2019). Indonesia insiden kasus TB 842.000 per tahun dan notifikasi kasus TB 569.899 maka masih ada sekitar $32 \%$ yang belum ternotifikasi karena belum terjangkau, belum terdeteksi maupun tidak terlaporkan (Indonesia, 2019). Studi yang menggambarkan faktor-faktor yang signifikan mempengaruhi perilaku pasien terhadap pengobatan Tuberculosis yang dapat diklasifikasikan menjadi dua kelompok, yaitu Kelompok studi yang menekankan pemanfaatan sistem formal, atau perawatan kesehatan (Hovell et al., 2003). Pengetahuan pasien tentang TB sangat penting dan merupakan tujuan utama dari strategi pengobatan TB. Petugas kesehatan sering menjadi sumber informasi utama tentang TB untuk pasien. Komunikasi yang efektif mengenai penyebab TB, gejalanya, pengobatannya, dan cara penyebarannya sangat penting, terutama di Indonesia di mana penyakit ini masih sangat banyak (WHO, 2014).
Kedekatan hubungan sosial antara petugas kesehatan dan pasien dapat meningkatkan pengetahuan dan kepatuhan pasien terhadap perilaku pencegahan infeksi (Pai et al., 2018). Kelompok kedua terdiri dari studi yang menekankan proses respons penyakit, atau perilaku pencarian pengobatan kesehatan. Studi ini menunjukkan bahwa keputusan untuk terlibat dengan pengobatan dipengaruhi oleh berbagai faktor seperti ekonomi, jenis kelamin, usia, status sosial, jenis penyakit, akses ke layanan dan persepsi kualitas layanan dan persepsi pelayanan kesehatan oleh karena itu Penelitian ini bertujuan untuk Mengidentifikasi faktor yang berhubungan dengan kepatuhan pasien terhadap pengobatan TB (Latunji, Akinyemi, \& Health, 2018).

\section{METODE PENELITIAN}

Metode penelitian dengan survei analitik cross sectional studi kasus. Sampel penelitian 43 orang penderita TB paru gagal dan Drop Out pada pengobatan tahun 2017 dan teknik pengambilan sampel dengan total sampling. Pengambilan data dikumpulkan menggunakan data primer hasil pengisian kuesioner responden dan data sekunder dari registrasi pengobatan $\mathrm{TB}$ di Puskesmas. Analisis data menggunakan Uji chi-square.

HASIL PENELITIAN

Tabel 1.1 Karakteristik Responden

\begin{tabular}{cccc}
\hline \multirow{2}{*}{ Karakteristik } & Variables & N (43) & \% \\
\hline Umur & Dewasa Awal (20-40) & 34 & 79,1 \\
& Dewasa Akhir (41-59) & 9 & 20,9 \\
& Lansia ( $\geq 60$ & 0 & 0 \\
Pendidikan & SD & 6 & 14 \\
& SMP & 8 & 18,6 \\
& SMA/SMK & 21 & 48,8 \\
Pekerjaan & Perguruan Tinggi & 8 & 18,6 \\
& Ibu Rumah Tangga & 16 & 37,2 \\
& PNS & 3 & 70,2 \\
Jenis kelamin & Pegawai Swasta & 13 & 25,6 \\
& Wiraswasta & 11 & 34,9 \\
Penghasilan & Laki-laki & 15 & 65,1 \\
keluarga & Perempuan & 28 & 23,3 \\
perbulan & 500.000-1.000.000 & 10 & 53,5 \\
& $1.000 .000-3.000 .000$ & 23 & 23,3 \\
\hline
\end{tabular}


Dari tabel diatas terlihat, mayoritas usia pada dewasa awal 34 orang (79,1\%), Pendidikan paling banyak pada tingkat SMA sejumlah 21 orang $(48,8 \%)$, dengan Pekerjaan mayoritas adalah Ibu Rumah Tangga 16 orang (37.2\%) Jenis kelamin mayoritas pada Perempuan 28 orang (65.1\%), Dan Penghasilan keluarga perbulan adalah pada rentang 1.000.000 - 3.000 .000 sejumlah 23 orang $(53.5 \%$

Tabel 1.2

Gambaran Pengetahuan Penderita Tentang TB Paru

\begin{tabular}{ccc}
\hline Pengetahuan & $\mathbf{N}=\mathbf{4 3}$ & $\mathbf{\%}$ \\
\hline Baik & 38 & 88.37 \\
Cukup & 3 & 6.98 \\
Kurang & 2 & 4.65 \\
\hline Total & 43 & $\mathbf{1 0 0}$ \\
\hline
\end{tabular}

Dari tabel diatas terlihat mayoritas penderita memiliki pengetahuan baik 38 orang (88.37\%), pengetahuan cukup 3 orang (6.98\%) dan Pengetahuan Kurang 2 orang (4.65\%).

Tabel 1.3

Hubungan jenis kelamin dengan kepatuhan berobat TB paru

\begin{tabular}{lcccc}
\hline \multicolumn{1}{c}{ Kelamin } & \multicolumn{2}{c}{ Kepatuhan } & & P \\
& Patuh & T. Patuh & Total & value \\
\hline Laki-laki & 12 & 3 & 15 & \multirow{2}{*}{0.014} \\
Perempuan & 28 & 0 & 28 & \\
\hline Total & 3 & 40 & 43 & \\
\hline
\end{tabular}

Dari tabel diatas terlihat berdasarkan jenis kelamin Perempuan dengan kepatuhan 28 orang dibandung Laki-laki 15 orang terhadap pengobatan Tuberculosis dan memiliki hubungan yang signifikan dengan nilai Pvalue 0.014.

Tabel 1.4

Hubungan Pengetahuan dengan kepatuhan berobat TB paru

\begin{tabular}{ccccc}
\hline Pengetahuan & \multicolumn{2}{c}{ Kepatuhan } \\
Patuh & $\begin{array}{c}\text { T } \\
\text { Patuh }\end{array}$ & Total & $\begin{array}{c}\text { P } \\
\text { value }\end{array}$ \\
\hline Baik & 35 & 3 & 38 & 0.424 \\
Cukup & 3 & 0 & 3 & \\
Kurang & 2 & 0 & 2 & \\
\hline Total & 40 & 3 & 43 & \\
\hline
\end{tabular}

Dari tabel diatas terlihat penderita dengan pengetahuan yang baik dengan kepatuhan 35 orang dibanding pengetahuan yang cukup 3 orang dan pengetahuan yang kurang 2 orang dan tidak ada hubungan antara pengetahuan dan kepatuhan penderita Tuberculosis dengan nilai $P$ value 0.424 .

Tabel 1.5

Hubungan Usia terhadap kepatuhan berobat pada penderita TB paru

\begin{tabular}{c|c|c|c|c|c}
\hline \multirow{2}{*}{ Usia } & \multicolumn{4}{|c|}{ Kepatuhan } & \multirow{2}{*}{ P } \\
\cline { 2 - 6 } & Patuh & \% & Tidak Patuh & \% & value \\
\hline Dewasa Awal & 21 & 48.84 & 0 & 0 & \multirow{2}{*}{0.469} \\
\hline Dewasa Menengah & 19 & 44.19 & 1 & 2.32 & \\
\hline Lansia > 60g & 2 & 4.65 & 0 & 0 & \\
\hline Total & $\mathbf{4 2}$ & $\mathbf{9 7 . 6 8}$ & $\mathbf{1}$ & $\mathbf{2 . 3 2}$ & \\
\hline
\end{tabular}

Dari Tabel diatas terlihat Usia deawasa awal 18 - 40 tahun dengan kepatuhan 21 orang dibanding usia dewasa menegah 40-65 tahun 19 orang dan lanjut usia $>90$ tahun 2 orang, dan tidak ada hubungan usia dan kepatuhan penderita Tuberculosis.

Tabel 1.6

Hubungan Pekerjaan dengan kepatuhan berobat TB paru

\begin{tabular}{c|c|c|c|c|c}
\hline \multirow{2}{*}{ Pekerjaan } & \multicolumn{4}{|c|}{ Kepatuhan } & \multirow{2}{*}{ P value } \\
\cline { 2 - 5 } & Patuh & $\mathbf{\%}$ & T Patuh & $\mathbf{\%}$ & \\
\hline Ibu Rumah Tangga & 16 & 37.21 & 0 & 0 & \multirow{2}{*}{0.025} \\
Pegawai Swasta & 13 & 30.23 & 0 & 0 & \\
Wiraswasta & 3 & 6.98 & 8 & 18.6 & \\
PNS & 3 & 6.98 & 0 & 0 & \\
\hline Total & 35 & $\mathbf{8 1 . 4}$ & $\mathbf{8}$ & $\mathbf{1 8 . 6}$ & \\
\hline
\end{tabular}


Dari tabel diatas terlihat Ibu rumah tangga dengan kepatuhan 16 orang dibanding pegawai swasta 13 orang, wiraswasta 3 orang dan PNS 3 orang, dan ada hubungan yang signifikat antara pekerjaan dengan kepatuhan berobat pada penderita tuberculosis.

Tabel 1.7

Hubungan Pengahsilan dengan kepatuhan berobat TB paru

\begin{tabular}{c|c|c|c|c|c}
\hline \multirow{2}{*}{ Penghasilan } & \multicolumn{3}{|c|}{ Kepatuhan } & \multirow{2}{*}{ P value } \\
\cline { 2 - 5 } & Patuh & $\%$ & $\begin{array}{c}\text { Tidak } \\
\text { Patuh }\end{array}$ & \% & \\
\hline $500.000-1000.000$ & 10 & 23.25 & 0 & 0 & \\
$1000.000-3000.000$ & 19 & 44.19 & 3 & 6.98 & 0.215 \\
$3000.000-5000.000$ & 11 & 25.58 & 0 & 0 & \\
\hline Total & 40 & 93.02 & 3 & $\mathbf{6 . 9 8}$ & \\
\hline
\end{tabular}

Dari Tabel diatas terlihat penderita dengan Penghasilan 1.000.000-3.000.000 dengan kepatuhan 19 orang dibanding penghasilan 3.000.000-5.000.000 sejumlah 11 orang dan penghasilan 500.000 - 1.000.000 (10) orang dan tidak ada hubungan antara penghasilan dengan kepatuhan berobat Tuberculosis.

\section{PEMBAHASAN}

Hasil penelitian menunjukkan faktor yang memiliki hubungan yang signifikan dengan kepatuhan penderita adalah jenis kelamin dan pekerjaan, hal ini sesuai dengan hasil penelitian sebelumnya yang mengatakan Perbedaan jenis kelamin akan mempengaruhi pengobatan tuberkulosis (TB) dimana wanita lebih patuh dibanding laki-laki dan laki-laki lebih banyak menderita TB dibanding perempuan namun tingkat kepatuhan lebih baik pada perempuan (Sirc, 1989). Perbedaan jenis kelamin antara laki-laki dengan perempuan pengobatan TB mempengaruhi kerentanan terjadinya infeksi dan juga perawatan kesehatan. Dampak sosial yang ditimbulkan berdasarkan penyakit TB dapat terjadi dari berbagai faktor, seperti bahaya yang dirasakan dan menular, atau penilaian negatif yang menghubungkan kondisi dengan perilaku menyalahkan korban karena menderita penyakit tersebut (Atre, Kudale, Morankar, Rangan, \& Weiss, 2004). Hal ini disebabkan karena laki-laki kurang memperhatikan kesehatannya dengan gaya hidup yang tidak sehat. Jenis kelamin lakilaki tidak patuh berobat dibandingkan dengan wanita. Beberapa teori menyatakan wanita lebih banyak melaporkan gejala penyakitnya, konsultasi dengan tenaga medis dikarenakan wanita cenderung memiliki perilaku lebih tekun dari laki-laki (Erawatyningsih, Purwanta, \& Subekti, 2009).

Selama ini Penyakit TB pada lakilaki sering diabaikan dibandingkan perempuan, padahal kasus kejadian $\mathrm{TB}$ pada laki-laki lebih banyak dari pada perempuan dikarenakan faktor ketidak patuhan dalam pengobatan (Horton, MacPherson, Houben, White, \& Corbett, 2016) dan angka kematian tingkat globalpun lebih tinggi laki-laki dari pada perempuan (Vissandjee, Mourid, Greenaway, Short, \& Proctor, 2016) namun dalam pengobatan TB tidak ada perbedaan jenis kelamin karena pada laki- laki dan perempuan akan sembuh pada waktu yang sama tergantung kepada lamanya pengobatan (Vissandjee et al., 2016).

Pekerjaan responden sebagai ibu rumah tangga lebih patuh dalam perawatan TB hal ini sejalan dengan penelitian (Rosenman \& Hall, 1996) pasien tuberkulosis yang pernah bekerja di industri tertentu mengalami peningkatan risiko pengembangan $\mathrm{TB}$, hal ini berarti pasien yang tinggal dirumah lebih patuh dalam pengobatan TB dibanding pasien yang bekerja, Pekerjaan memiliki hubungan secara signifikan dengan 
kematian akibat TB pada pekerjaan konstruksi termasuk: tukang batu dan bata; tukang kayu; atap; dan kuli bangunan (Rosenman \& Hall, 1996). Begitu juga dengan orang yang bekerja di Rumah Sakit lebih rentan terkena TB dibandingkan yang bekerja diluar Rumah Sakit (Kigozi, Heunis, Engelbrecht, Janse Van Rensburg, \& Van Rensburg, 2017). Pengetahuan, usia dan pendapatan keluarga tidak ada hubungan dengan kepatuhan pengobatan $\mathrm{TB}$, ini dikarenakan Pengetahuan TB, sikap dan praktik memiliki pengaruh terhadap pendidikan kesehatan di fasilitas pelayan kesehatan (Kigozi et al., 2017), pengetahuan akan meningkat apabila informasi kesehatan melalui pendidikan kesehata yang diterima, namun tidak menjamin pengetahuan yang baik akan berpengaruh terhadap perilaku penderita. Pengetahuan tentang TB dan kepercayaan untuk kemajuan pengobatan mempengaruhi penderita untuk memilih menyelesaikan pengobatan. Kepercayaan budaya juga mempengaruhi penyembuhan.

Begitu juga usia terhadap kepatuhan berobat, semakin bertambah usia tidak menjamin pasien patuh terhadap pengobatan. Penelitian ini sesuai dengan teori bahwa umur tidak berpengaruh terhadap tindakan seseorang karena adanya faktor perantara seperti sikap dan faktor lain.

\section{KESIMPULAN}

Adanya hubungan Jenis kelamin dan pekerjaan terhadap kepatuhan berobat penderita Tuberculosis, sedangkan Usia, Pengetahuan dengan Pendapatan tidak ada hubungan dengan kepatuhan berobat penderita Tuberculosis.

\section{DAFTAR PUSTAKA}

Atre, S. R., Kudale, A. M., Morankar, S. N., Rangan, S. G., \& Weiss, M. G. (2004). Cultural concepts of tuberculosis and gender among the general population without tuberculosis in rural
Maharashtra , India. 9(11), 1228-1238.

Erawatyningsih, E., Purwanta, \& Subekti, H. (2009). Faktor-Faktor yang Mempengaruhi Ketidakpatuhan Berobat pada Penderita Tuberkulosis Paru. Faktor-Faktor Yang Mempengaruhi Ketidakpatuhan Berobat Pada Penderita Tuberkulosis Paru, 25(3), 117-124. https://doi.org/10.22146/bkm.3558

Horton, K. C., MacPherson, P., Houben, R. M. G. J., White, R. G., \& Corbett, E. L. (2016). Sex Differences in Tuberculosis Burden and Notifications in Low- and Middle-Income Countries: A Systematic Review and Meta-analysis. PLoS Medicine, 13(9), 1-23. https://doi.org/10.1371/journal.pmed .1002119

Hovell, M., Blumberg, E., Gil-Trejo, L., Vera, A., Kelley, N., Sipan, C., ... Moser, K. (2003). Predictors of adherence to treatment for latent tuberculosis infection in high-risk Latino adolescents: A behavioral epidemiological analysis. Social Science and Medicine, 56(8), 1789-1796. https://doi.org/10.1016/S02779536(02)00176-4

Indonesia, K. (2019). TB Indonesia. Retrieved from

https://www.tbindonesia.or.id/page/v iew/11/situasi-tbc-di-indonesia

Kigozi, N. G., Heunis, J. C., Engelbrecht, M. C., Janse Van Rensburg, A. P., \& Van Rensburg, H. C. J. D. (2017). Tuberculosis knowledge, attitudes and practices of patients at primary health care facilities in a South African metropolitan: Research towards improved health education. BMC Public Health, 17(1), 1-8. https://doi.org/10.1186/s12889-0174825-3

Latunji, O. O., Akinyemi, O. O., \& Health, F. (2018). FACTORS INFLUENCING HEALTH-SEEKING BEHAVIOUR AMONG CIVIL SERVANTS IN IBADAN, NIGERIA. 16(1).

Pai, M., Delavallade, C., Huddart, S., Bossuroy, T., Pons, V., \& Baral, S. (2018). Knowledge about tuberculosis and infection prevention behavior: A nine city longitudinal study from India. PLoS ONE, 13(10), 1-15. https://doi.org/10.1371/journal.pone. 
0206245

Rosenman, K. D., \& Hall, N. (1996). Occupational risk factors for developing tuberculosis. American Journal of Industrial Medicine, 30(2), 148-154.

https://doi.org/10.1002/(SICI)10970274(199608)30:2<148::AID-

AJIM5>3.0.CO;2-X

Sirc, G. (1989). Gender and. Freshman English News, 18(1), 4-11.

Vissandjee, B., Mourid, A., Greenaway, C. A., Short, W. E., \& Proctor, J. A. (2016). Searching for sex- and gender-sensitive tuberculosis research in public health: Finding a needle in a haystack. International Journal of Women's Health, 8, 731-742. https://doi.org/10.2147/IJWH.S11975 7

WHO. (2014). The End TB Strstegy. 1-25.

WORLD HEALTH ORGANISATION. (2019). Tuberculosis who. Retrieved from https://www.who.int/news-room/factsheets/detail/tuberculosis 